\title{
Tropical Disease, the Hydra Technology Will Not Slay
}

\author{
Jennifer M. Grant*, B.S., M.D.C.M.
}

\section{TROPICAL MEDICINE FROM 1978 TO 2000}

In September 1978, the World Health Organization (WHO) declared that the year 2000 should mark "the attainment by all peoples of the world ... of a level of health that will permit them to lead a socially and economically productive life" (1). Clearly, this goal has not been achieved. However, major strides have been made in the past 22 years since this statement was signed to greatly improve the health of the world's population. Changes have especially benefited those in middle and lower income countries.

Amongst our successes are the celebrated eradication of smallpox in 1980 and the elimination of polio from the Americas in recent years. With these successes in hand, the WHO has assigned the year 2000 to be the date for the total eradication of Polio and Guinea worm as well as the elimination of leprosy, neonatal tetanus, Chagas' disease and iodine deficiency (2). Health officials foresee the future elimination of filaria and oncocerchiasis. The Expanded Program on Immunization (EPI) saves an estimated 3 million lives per year (3). Massive efforts have achieved a feasible cold chain to provide well refrigerated vaccines to even the most remote areas of the world and primary health care is being provided for an increasing number of the people (4). Provision of primary care and availability of refrigeration alone will infinitely facilitate initiation of further campaigns.

Elimination efforts have been greatly successful worldwide. Guinea worm incidence has been reduced from 3.6 million cases in 1986 to 58,515 in 1997 (99.9\% of remaining cases are in Africa) (5). Polio

\footnotetext{
* To whom correspondence should be addressed: Centre for the Study of Host Resistance, Montreal General Hospital, 1650 Cedar Ave. Montreal, Quebec, H3G 1A4, Canada.
}

incidence has been reduced from $>35,000$ cases in 1988 to $\sim 5000$ cases in 1997 (6). Primary care and nutritional interventions have decreased child mortality from 90 per 1000 live births in 1975 to 59 per 1000 live births in 1995 (4). Motherhood is safer than it has ever been. Life expectancy has increased from 61 years to 66 years, and the chance of dying before age 5 has decreased from 124 per 1000 to 83 per 1000 since 1978 (7). These improvements have occurred even in the face of the overwhelming increase in mortality brought about by the HIV pandemic (see preceding paper, 8).

\section{LINGERING PROBLEMS AND NEW THREATS}

Based on these optimistic data, Gilles and Lucas argue that with respect to tropical medicine we are now in the stage of deployment - the stage in which we gain the upper hand over tropical diseases and work towards their eradication (9). This has a certain grain of truth to it. Ischaemic heart disease and cerebrovascular disease are now ranked first and second as causes for mortality worldwide (Table 1), pushing infectious diseases out of the way for the first time in history (7), though there is striking regional variation that warrants attention (see below). We have the technology to treat most major infectious diseases and the public health knowledge to greatly reduce others. However, Gilles and Lucas are too optimistic about the possibility of our mastering diseases that have repeatedly eluded our control in the past. We have had to admit defeat in the face of overwhelming obstacles in some elimination efforts. It has been widely accepted that many diseases such as malaria and tuberculosis cannot be eradicated from the human population with present technology; even optimists speak only of their reduction and control (10). In addition, we are facing a growing array of new and re-emerging infectious diseases including HIV, dengue, 
Table 1. Leading causes of mortality and DALYs in all Member States and their ranks in WHO Regions ${ }^{\mathrm{a}}$

\begin{tabular}{|c|c|c|c|c|c|c|c|c|c|c|c|c|c|c|}
\hline & \multicolumn{2}{|c|}{$\begin{array}{c}\text { All Member } \\
\text { States } \\
\end{array}$} & \multicolumn{2}{|c|}{ Africa } & \multicolumn{2}{|c|}{ The Americas } & \multicolumn{2}{|c|}{$\begin{array}{c}\text { Eastern } \\
\text { Mediterranean } \\
\end{array}$} & \multicolumn{2}{|c|}{ Europe } & \multicolumn{2}{|c|}{$\begin{array}{c}\text { South- } \\
\text { East Asia } \\
\end{array}$} & \multicolumn{2}{|c|}{$\begin{array}{c}\text { Western } \\
\text { pacific }\end{array}$} \\
\hline & Rank & $\begin{array}{l}\text { \% of } \\
\text { Total }\end{array}$ & Rank & $\begin{array}{l}\% \text { of } \\
\text { Total }\end{array}$ & Rank & $\begin{array}{l}\% \text { of } \\
\text { Total }\end{array}$ & Rank & $\begin{array}{l}\text { \% of } \\
\text { Total }\end{array}$ & Rank & $\begin{array}{l}\text { \% of } \\
\text { Total }\end{array}$ & Rank & $\begin{array}{l}\text { \% of } \\
\text { Total }\end{array}$ & Rank & $\begin{array}{l}\% \text { of } \\
\text { Total }\end{array}$ \\
\hline \multicolumn{15}{|l|}{ Deaths } \\
\hline Ischemic heart disease & 1 & 13.7 & 9 & 2.9 & 1 & 17.9 & 1 & 13.6 & 1 & 25.5 & 1 & 13.8 & 3 & 11.1 \\
\hline Cerebrovascular disease & 2 & 9.5 & 7 & 4.7 & 2 & 10.3 & 5 & 5.3 & 2 & 13.7 & 4 & 6.5 & 1 & 14.3 \\
\hline Acute lower respiratory infections & 3 & 6.4 & 3 & 8.2 & 3 & 4.2 & 2 & 9.1 & 4 & 3.6 & 2 & 9.3 & 4 & 4.0 \\
\hline HIV/AIDS & 4 & 4.2 & 1 & 19.0 & 13 & 1.8 & 27 & 0.4 & 42 & 0.2 & 8 & 2.2 & 42 & 0.2 \\
\hline Chronic obstructive pulmonary disease & 5 & 4.2 & 14 & 1.1 & 6 & 2.8 & 10 & 1.7 & 5 & 2.7 & 11 & 1.6 & 2 & 12.0 \\
\hline Diarrheal diseases & 6 & 4.1 & 4 & 7.6 & 10 & 2.0 & 3 & 7.4 & 22 & 0.7 & 3 & 6.6 & 17 & 1.2 \\
\hline Perinatal conditions & 7 & 4.0 & 5 & 5.5 & 7 & 2.6 & 4 & 7.3 & 13 & 1.2 & 5 & 6.0 & 10 & 2.2 \\
\hline Tuberculosis & 8 & 2.8 & 11 & 2.2 & 19 & 1.0 & 7 & 3.7 & 23 & 0.6 & 6 & 5.1 & 9 & 2.9 \\
\hline Cancer of trachea/bronchus/lung & 9 & 2.3 & 38 & 0.3 & 4 & 3.2 & 20 & 1.0 & 3 & 4.2 & 15 & 1.2 & 6 & 3.6 \\
\hline Road traffic accidents & 10 & 2.2 & 12 & 1.8 & 5 & 3.1 & 9 & 1.9 & 8 & 1.9 & 7 & 2.5 & 12 & 2.0 \\
\hline \multicolumn{15}{|l|}{ DALY's } \\
\hline Acute lower respiratory infections & 1 & 6.0 & 4 & 7.0 & 9 & 2.9 & 2 & 8.1 & 8 & 2.5 & 1 & 8.1 & 4 & 3.9 \\
\hline Perinatal conditions & 2 & 5.8 & 5 & 6.2 & 5 & 4.2 & 1 & 8.2 & 5 & 2.9 & 2 & 7.9 & 5 & 3.7 \\
\hline Diarrheal diseases & 3 & 5.3 & 3 & 7.5 & 8 & 3.0 & 3 & 7.7 & 17 & 1.6 & 3 & 7.2 & 13 & 1.9 \\
\hline HIV/AIDS & 4 & 5.1 & 1 & 16.6 & 13 & 2.0 & 7 & 2.8 & 46 & 0.4 & 12 & 2.2 & 36 & 0.6 \\
\hline Unipolar major depression & 5 & 4.2 & 11 & 1.7 & 1 & 5.7 & 6 & 3.6 & 3 & 5.5 & 4 & 4.0 & 2 & 6.5 \\
\hline Ischemic heart disease & 6 & 3.8 & 20 & 0.9 & 2 & 4.9 & 5 & 3.7 & 1 & 9.7 & 5 & 3.8 & 7 & 3.5 \\
\hline Cerebrovascular disease & 7 & 3.0 & 13 & 1.5 & 6 & 3.5 & 12 & 1.8 & 2 & 5.6 & 13 & 2.1 & 3 & 5.1 \\
\hline Malaria & 8 & 2.8 & 2 & 10.6 & 80 & 0.1 & 16 & 1.5 & 97 & 0.0 & 39 & 0.6 & 60 & 0.2 \\
\hline Road traffic accidents & 9 & 2.8 & 9 & 1.9 & 4 & 4.7 & 11 & 2.1 & 4 & 3.7 & 8 & 2.9 & 9 & 2.8 \\
\hline Measles & 10 & 2.2 & 6 & 5.3 & 92 & 0.0 & 8 & 2.7 & 67 & 0.2 & 11 & 2.2 & 48 & 0.3 \\
\hline
\end{tabular}

a Reproduced from p. 98 of reference 7.

DALY: Disability-Adjusted Life Years.

hepatitis C, ebola, lassa, prion diseases, plus an array of old diseases becoming resistant to our current antibiotics. A relative newcomer, HIV/AIDS has climbed up the scale to become the 4th leading cause of death in the 20 years since its discovery and it is, in fact, the leading cause of death in Africa (7).

Many emerging diseases are being given the opportunity to propagate themselves largely because human expansion, human migration and patterns of land use are changing the way in which populations interact with the environment (11). It is most likely that we will understand these changes only with the perspective of several decades if not centuries. However, what is certain is that the poor of the world are disproportionately affected (12). This burden of disease is due to both the geographic distribution of diseases and because political disarray and poor access to health care exacerbates epidemic conditions. Intimately linked with this phenomenon is the problem of an exponentially growing population in areas with already marginal water supply and food production (11). Many organizations and individuals are trying to address the issues of environmental interaction of diseases. However, any public health interventions to new health threats are necessarily reactive as we are unable to predict our effect on ecosystems before they happen. Despite this fact, many environmental innovations are greatly improving health for known risks. For example water initiatives begun during the "Decade of Water" (1981-1990) have increased access to safe water from $20 \%$ to $66 \%$ of the world's population (4).

New and re-emerging diseases threaten the tenuous advantage that humans have gained with technological advances. It is difficult to imagine a repeat of the incredible monetary and intellectual resources that have been invested in fighting HIV/AIDS. Should we have to fight a new disease every 20 years or even every 50 years, we would very soon run out of the capital necessary to investigate new treatments and approaches. Furthermore, without maximal use of these technologies, their full impact is not being realized (8). Although the Expanded Program on Immunization has been very successful, the campaign has still not managed to achieve the modest goal of minimum $80 \%$ coverage; in fact, the world average for vaccine coverage is $80 \%$ (4). This means that many countries are vaccinating at a significantly lower rate, thereby allowing reservoirs of disease to be perpetuated. These vaccination rates fall dismally short of the necessary 


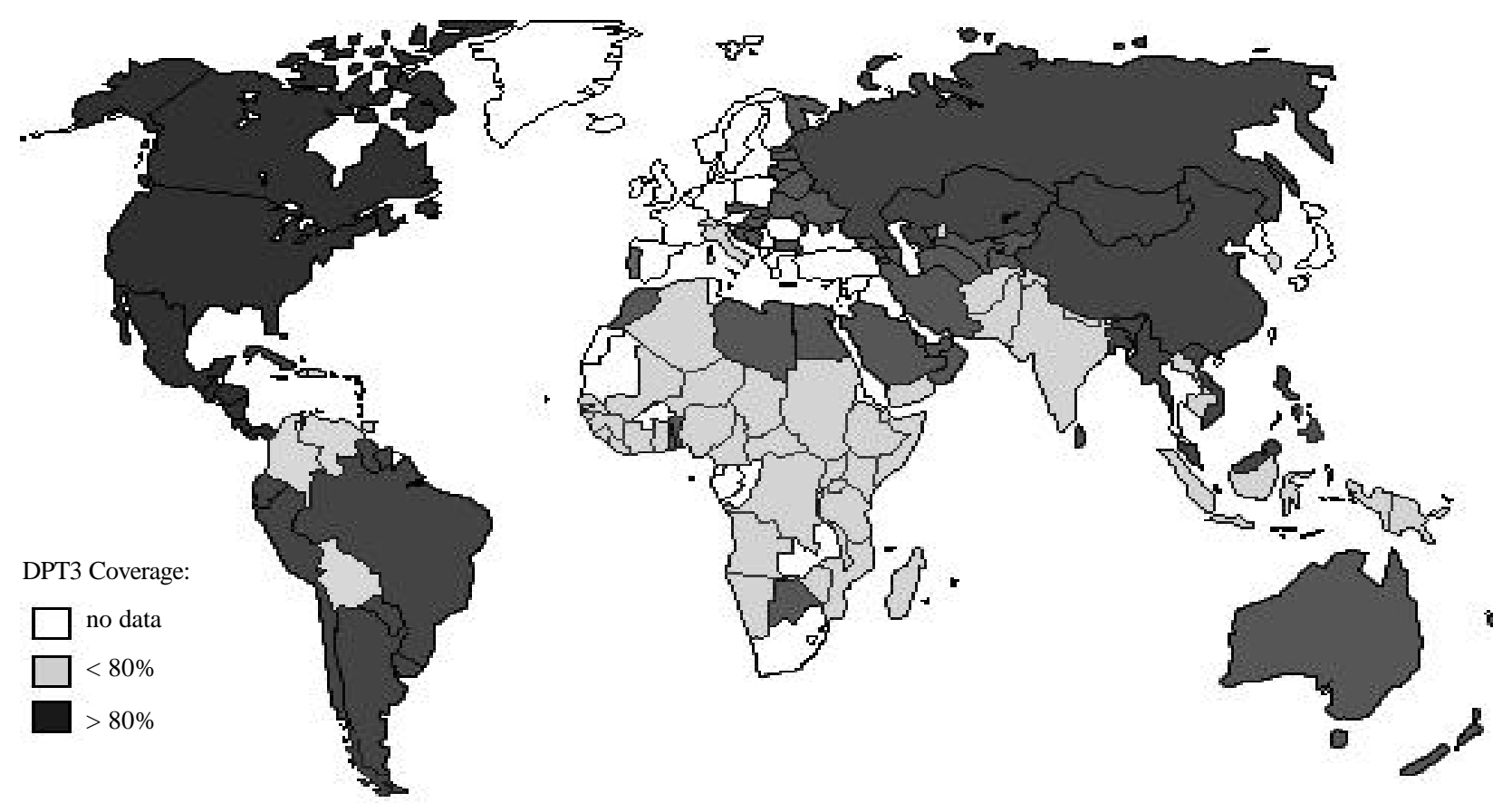

Figure 1 Proportion of vaccine coverage of DPT for children in the target age range, 1998. Modified from http://www.who.int/vaccinessurveillance/graphics/NY_graphics/dtp3.gif.

95\% coverage needed for the eradication of measles (13). Low vaccination rates are especially prevalent in lower income countries, especially those in Africa (Figure 1). Tuberculosis, despite the presence of adequate drugs for treatment (leaving aside the issue of emerging resistance), continues to affect nearly 2 million people, almost all in Africa and Southeast Asia (7). Effective AIDS treatments are available only to the richest of the world's population (8). Even technology as simple as oral rehydration has failed to reach many children at risk for diarrheal disease.

\section{ROLE OF POVERTY}

The major causes of productive life years lost now, as 100 years ago, remain acute respiratory diseases, perinatal conditions and diarrheal diseases; these same diseases are, in fact, leading causes of death in certain regions of the world (see Table 1). These are diseases of poverty. Failure to treat them is a problem of poverty. It is a truism to point out that economic, educational and physical development are the backbone of health improvement. However, despite universal acknowledgement that these are the most important factors in health, they remain the major stumbling blocks to progress (see first paper in Focus, 12). Present indicators show that poverty is increasing worldwide, not decreasing (14). It is not improved vaccine adjuvants or antibiotics that will solve health problems related to poverty, but the harder road of improving nutrition, education, social equality and access to resources.
One of the impediments to development is the present structure of the world economy. Some poorer countries have made remarkable strides in breaking out of Third World poverty. With improved economic performance has come better health infrastructure and better nutrition. Latin America, Southeast Asia and parts of Africa have significantly improved the wealth and health of their citizens. For example, between 1994 and 1997 Peru has decreased the number of its citizens under the poverty line from $53 \%$ to $49 \%$; Morocco: $26 \% \rightarrow$ 13\% (1985-1991); India: $40.9 \% \rightarrow$ 35\% (1992-1994); Dominican Republic: $24.5 \% \rightarrow$ 20.6\% (1989-1992) (15). However, these are marginal gains compared to those countries that are losing economic ground. For example, the poverty rate in Haiti has increased from $65 \%$ to $81 \%$ (1987-1995); Algeria: $12 \% \rightarrow 22.6 \%$ (1988-1995); Zambia: $68 \% \rightarrow$ $86 \%$ (1991-1993) (15). Comparing these two sets of figures shows that economic growth is a slow and fragile process and can be easily counterbalanced by disastrous economic failure. Nine of the 16 poorest countries in the world are in Africa (Figure 2). This pattern reflects the growing poverty of Africa relative to the rest of the developing world. Health indicators clearly indicate that Sub-Saharan Africa in particular lags behind the rest of the world (Figure 3). Infant mortality rates have declined from 115 per 1000 live births to 91 per 1000 since 1980 (7). However, this statistic compares unfavourably with Latin America and the Carribean's 32 deaths per 1000 live births (7). 


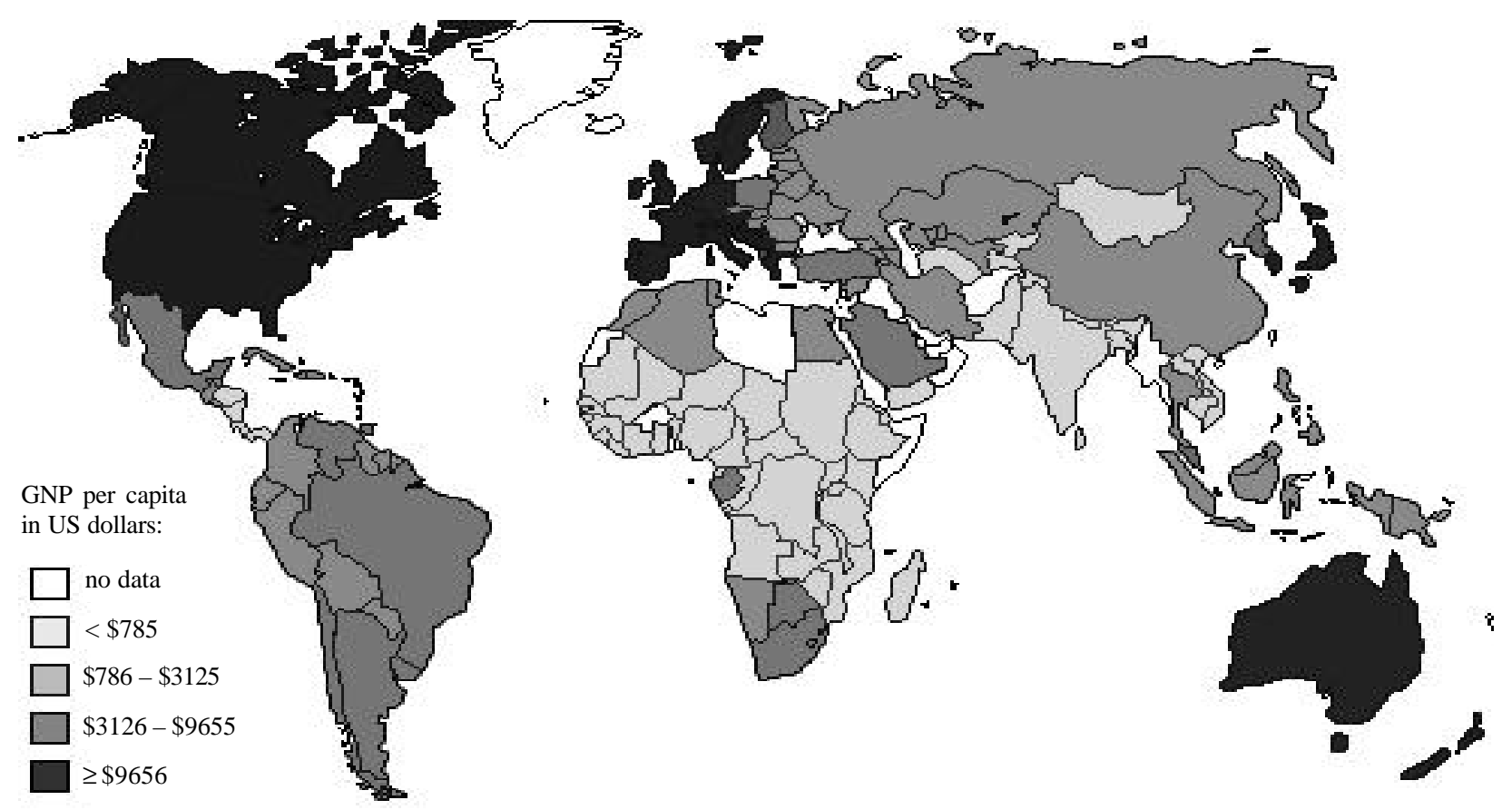

Figure 2. Regional variation in wealth. World map shows gross national product (GNP) per capita, 1997. Modifed from the World Bank Group web site; links to maps available from http://www.worldbank.org/data/maps/index.html.

Even in relative terms, Africa has experienced only a $20 \%$ decrease in infant mortality, compared to the $46 \%$ decrease during the same time period in Latin America. As pointed out by Heath and Haines (12), health indicators (as opposed to purely economic indicators) reflect the multidimensional nature of poverty. Improvement in health indicators is a true reflection of development.

The reason for these growing disparities is that world patterns of trade are excluding countries that lack basic economic infrastructure. This may reflect the need for increasingly trained workers to fuel technologically based industry. This phenomenon is a mirror of what is happening in First World society in which the poorly educated are excluded from many economic opportunities and have significantly poorer health than their richer compatriots (12). This in turn makes the road to economic development more difficult. Poor health is a significant impediment to improved economic performance, a fact that creates an economic and health spiral that can be disastrous (12). Whatever the reason, it is fair to say that world patterns of trade are exacerbating the differences between the haves and the have-nots.

\section{CHALLENGES IN TROPICAL MEDICINE}

One of the fundamental cruxes of finding new ways to treat tropical disease is the structure of research funding. Drug companies fund research because there is a profit to be made. If a drug is intended for a market that cannot generate a profit, it is not in a company's best interest to fund the research. Government development agencies, non-government organizations (NGOs), the United Nations and the World Bank have the broader mandate of addressing the underlying causes of poor health. However, these players in international health research suffer from insufficient funding. Government agencies have had a poor record with funding over the past ten years. For example, the Canadian International Development Agency has had its funding cut to a miniscule $0.30 \%$ of GNP down from $0.31 \%$ the previous year $(16,17)$. Other organizations are dependent on donors to provide their funding. Should there be a conflict with a donor's interests or a change in political sentiment domestically, funding can be withheld, as it has been by the United States. International organizations are also in conflict with each other. UNICEF's primary care structure may be undone the next year by a World Bank decentralization plan that fundamentally alters health care delivery. However, recent developments have given cause for optimism. Despite the lack of profit motive, drug companies are beginning to contribute their expensive discoveries to the benefit of those who cannot afford to pay for them. Both Merck and Smith-Klein-Becham have been instrumental in elimination campaigns by donating Ivermectin and Albendazole to the oncocerchiasis and filaria campaigns, respectively. However, these donations rely on a profitable domestic market to be feasible and to fuel research interest. They are also post 

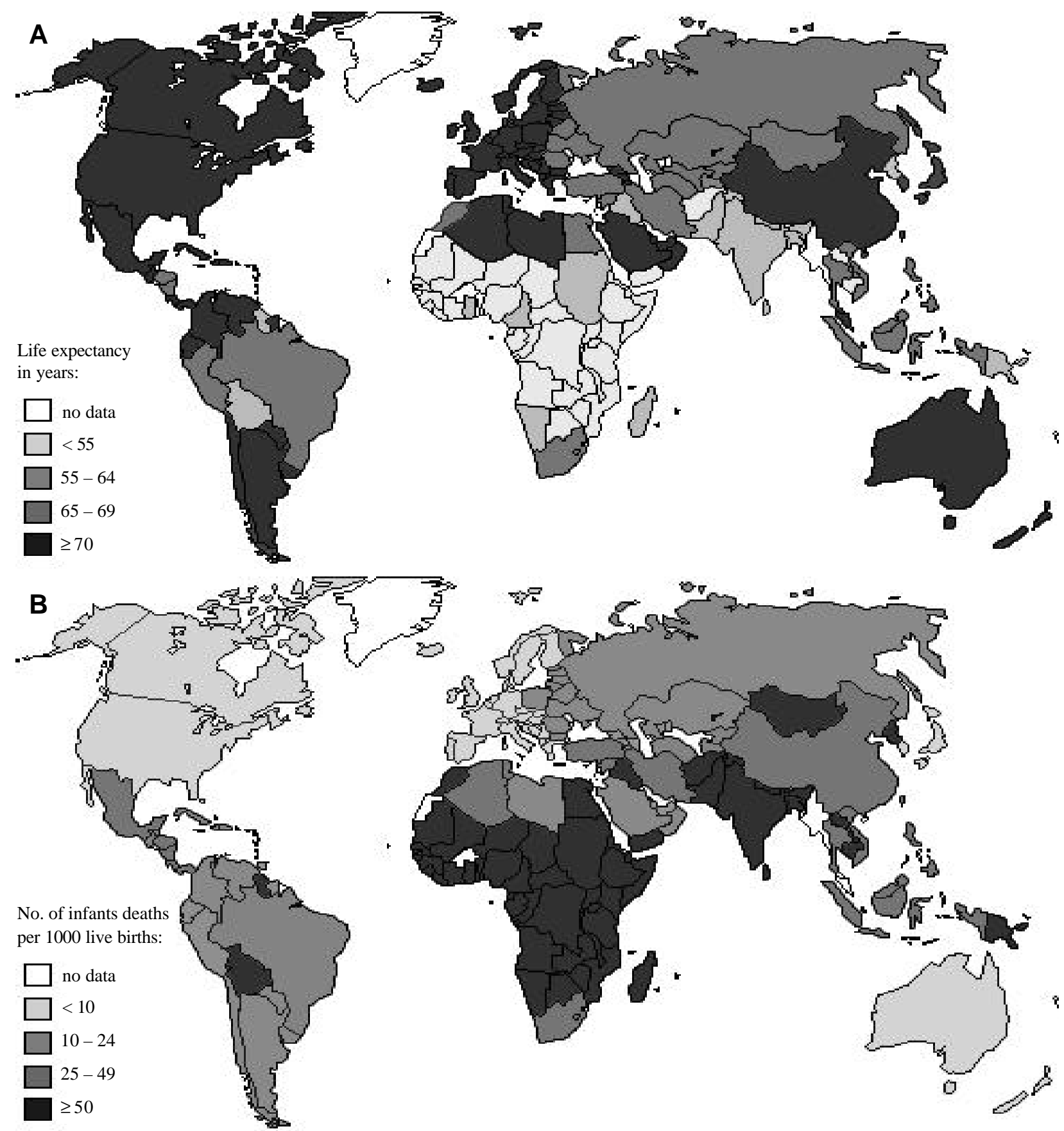

Figure 3. Regional variation in health indices, 1997. A: Life expectancy. B: Infant mortality rates. Notice the strong regional correlation between poor health and poverty. Modifed from the World Bank Group web site; links to maps available from http://www. worldbank.org/data/maps/index.html.

hoc donations and do not help to address new disease threats as they develop in the tropical world. What is needed is investment in innovative ways to treat diseases that will not necessarily guarantee a profit.

Even more importantly, disease prevention must be addressed. Adequate supply of food and clean water, improved education, and the provision of primary health care are the foundations for improving health.

\section{CONCLUSION}

Despite adequate reason for optimism, those interested in tropical medicine should not declare victory yet. There are numerous obstacles to cross before we can turn our attention to the eradication of tropical disease. Those that are of greatest importance are poverty, poor infrastructure, lack of funding, poor coordination of efforts and the unpredictable nature of newly emerging 
diseases. Until we have managed to understand and have started to control these factors, we will be unable to advance on those diseases that continue to cause enormous morbidity and mortality in developing countries.

\section{AKNOWLEDGEMENTS}

The author would like to gratefully acknowledge the editorial support offered by Dr. Brian Ward. She also wishes to thank Ahsan Alam for preparing the figures.

\section{REFERENCES}

1. The Alma-Ata conference on primary health care. WHO Chronicle 32: 409-430; 1978.

2. World Health Organization. Disease Eradication/Elimination Goals. http://www.who.int/aboutwho/en/disease_er.htm. 1999.

3. Cutts FT. Advances and challenges for the expanded programme on immunization. British Medical Bulletin 54: 445-461; 1998.

4. World Health Organization. Primary health care in the $21 \mathrm{st}$ century is everybody's business. Press release WHO/89. http:// www.who.int/inf-pr-1998/en/pr98-89.html. 27 November, 1998.

5. World Health Organization, Division of Control of Tropical Diseases. Dracunculiasis Eradication Progress. http://www. who.int/ctd/html/dracprogress.html. 1998.

6. World Health Organization, Division for Vaccines and other Biologicals. Global Status of Polio Eradication. http://www. polioeradication.org/global_status.html. 1999.

7. World Health Organization. The World Health Report 1999 -
Making a Difference. Geneva: WHO; 1999.

8. Rao VB. HIV in the developing world - meeting the challenge of the growing dichotomy. McGill Journal of Medicine 5: 121126; 2000.

9. Gilles HM, Lucas AO. Tropical medicine: 100 years of progress. British Medical Bulletin 54: 269-280; 1998.

10. Dowdle WR. The principles of disease elimination and eradication. Bulletin of the Wolrd Health Organization 76 (suppl 2): 22-25; 1998.

11. McMichael AJ, Patz J, Kovats RS. Impacts of global environmental change on future health and health care in tropical countries. British Medical Bulletin 54: 475-488; 1998.

12. Heath I, Haines A. Joining the fight against poverty: open invitation from the International Poverty and Health Network to all health professionals. McGill Journal of Medicine 5: 118-120; 2000.

13. Flugsrud LB, Rld TO, Aasen S, Berdal BP. Measles antibodies and herd immunity in 20- and 40-year-old Norwegians. Scandinavian Journal of Infectious Diseases 29: 137-140; 1997.

14. Guerrant RL, Blackwood BL. Threats to global health and survival: the growing crises of tropical infectious diseases - our “unfinished agenda". Clinical Infectious Diseases. 28: 966-986; 1999.

15. World Bank, World Development Report 1999 - Entering the 21st Century. LOCATION: World Bank Group; 1999.

16. CIDA. Statistical report on official development assistance 1997-1998. Hull, Quebec: Statistical analysis section international development centre policy branch; 1999.

17. MacLean JD, Ward BJ. First the bad news. Canadian Medical Association Journal 157: 1675-1676; 1997.

Jennifer Grant, BS, MDCM received her Bachelor of Science in molecular biophysics and biochemistry from Yale University (Berkeley College) in 1996. She received her MDCM from McGill University in May 2000. In July she will begin a residency in internal medicine at McGill University. Her interests include tropical medicine and infectious disease. 